\title{
Arteriovenous Malformations of the Brain in Children: A Forty Year Experience
}

\author{
Douglas Kondziolka, Robin P. Humphreys, Harold J. Hoffman, \\ E. Bruce Hendrick and James M. Drake
}

\begin{abstract}
Despite the great capacity for the pediatric brain to recover from stroke, the morbidity and mortality in children who harbor an arteriovenous malformation (AVM) remains high. This study examines the clinical data and management experience with 132 patients with brain AVM from 1949 to 1989. Although the high tendency for a childhood AVM to present with hemorrhage (79\%) remained constant for the forty year study period, the associated morbidity and mortality of hemorrhage changed. The mortality rate from hemorrhage for the entire series was $25 \%$, which was reduced from $39 \%$ to $16 \%$ after the introduction of computed tomography. The mortality from AVM hemorrhage since 1975 was dependent on location; 8 of 14 patients $(57 \%)$ with a cerebellar AVM died from hemorrhage while only 2 of 44 patients $(4.5 \%)$ with a cerebral hemisphere AVM died $(\mathrm{p}<0.0001)$. Sixteen children $(12 \%)$ presented with a chronic seizure disorder. Surgical excision of the malformation resulted in complete seizure control off anti-convulsant medication in $73 \%$ of patients. Although $21 \%$ of patients were treated non-operatively (many with terminal poor-grade hemorrhage), $79 \%$ had a surgical procedure with total AVM excision achieved in 70 patients (53.1\%). Complete AVM resection was followed by a normal neurological outcome in 47 children $(67 \%)$. Most partial excisions ( $n=9)$ and clipping of feeding arteries $(n=7)$ were performed in the early years of this study, and did not provide protection from rehemorrhage. Although conservative management has been advocated for selected non-hemorrhagic AVMs, we conclude that essentially all children with an AVM should be treated in order to eliminate the risk of hemorrhage. Long-term conservative management in pediatric patients is warranted only in patients with large AVMs not amenable to treatment using current multimodality techniques.
\end{abstract}

RÉSUMÉ: Malformations artério-veineuses cérébrales chez les enfants: quarante ans d'expérience. Bien que le cerveau de l'enfant ait un potentiel considérable de récupération après un accident cérébro-vasculaire, la morbidité et la mortalité chez les enfants qui sont porteurs de malformations artério-veineuses (MAV) demeurent élevées. La présente étude examine les données cliniques et l'expérience de traitement chez 132 patients avec MAV cérébrale, de 1949 à 1989. Même si la forte tendance pour une MAV de se présenter dans l'enfance par une hémorragie (79\%) est demeurée constante pendant la période de quarante ans de l'étude, la morbidité et la mortalité qui y sont associées ont changé. Le taux de mortalité due à l'hémorragie pour la série entière était de $25 \%$, ce taux s'abaissant de $39 \%$ à $16 \%$ après l'introduction de la tomodensitométrie. Depuis 1975, la mortalité due à une hémorragie de la MAV dépendait de sa localisation; 8 des 14 patients (57\%) avec MAV cérébelleuse sont décédés d'une hémorragie, alors que seulement 2 des 44 patients $(4.5 \%)$ avec MAV d'un hémisphère cérébral sont décédés $(\mathrm{p}<0.0001)$. Seize enfants $(12 \%)$ se sont présentés avec un tableau convulsif chronique. L'excision chirurgicale de la malformation a amené un contrôle complet des crises, sans médication anticonvulsivante, chez $73 \%$ des patients. Même si $21 \%$ des patients ont été traités sans avoir recours à la chirurgie, (plusieurs étaient porteurs d'une hémorragie terminale, d'emblée à mauvais pronostic), $79 \%$ ont subi une intervention chirurgicale avec excision totale de la MAV chez 70 patients $(53.1 \%)$. Une résection complète de la MAV a été suivie d'une issue neurologique normale chez 47 enfants $(67 \%)$. La plupart des excisions partielles $(\mathrm{n}=$ 9) et la ligature des artères nourricières $(n=7)$ ont étê réalisées dans les premières années de cette étude et n'ont pas assuré de protection contre une nouvelle hémorragie. Bien que le traitement conservateur ait été préconisé pour certaines MAVs qui n'ont pas saigné, nous concluons que tous les enfants avec une MAV devraient être traités afin d'éliminer le risque d'hémorragie. Le traitement conservateur à long terme chez les patients pédiatriques est justifié seulement chez les patients porteurs de grosses MAVs qui ne sont pas accessibles au traitement utilisant les techniques multimodales actuelles.

Can. J. Neurol. Sci. 1992; 19:40-45

From the Division of Neurosurgery, Hospital for Sick Children, University of Toronto, Toronto

Received June 28, 1991. Accepted August 7, 1991

Reprint requests to: Robin P. Humphreys, Division of Neurosurgery, Hospital for Sick Children, 555 University Avenue, Toronto, Ontario, Canada M5G 1 X8 
Arteriovenous malformations (AVM) of the brain are a common cause of hemorrhagic stroke in the pediatric population. In comparison to adults where hemorrhage, seizures, headache, and progressive neurological deficits are the common presenting manifestations, the majority of children (age to 18 years) suffer a hemorrhagic ictus as the initial syndrome. Due to this high hemorrhage risk and its attendant morbidity and mortality, surgical extirpation of the malformation should be the goal of treatment. This study reports the clinical information and treatment results from the management of 132 patients with brain AVM from 1949 to 1989 , and contrasts the childhood AVM from that of the adult.

Arteriovenous malformations are considered to be of congenital origin ${ }^{1-4}$ and most series note a common age of presentation at 20 to 40 years..$^{5-9}$ Although this may suggest a latency in the evolution of the malformation, it is important that $20 \%$ of AVMs entered into the Co-operative Study were diagnosed before the age of 20 years. ${ }^{10}$ This report excludes children with vein of Galen aneurysms, dural malformations, cavernous or venous angiomas, and capillary telangiectasia. In our general referral population, AVMs represented a significant proportion of pediatric stroke with a prevalence three times greater than saccular aneurysm in causing intracerebral hemorrhage. ${ }^{11}$

\section{Materials AND Methods}

All clinical, operative, radiologic and pathological records of children who presented with arteriovenous malformations of the brain from 1949 to 1989 were examined. Although the definition of "children" may be arbitrary, we selected birth to 18 years - the age range treated at our institution. All AVM were defined by angiography or pathological examination. Ten patients had angiographically occult vascular malformations (AOVM). All were verified histologically to be true arteriovenous malformations. Hemorrhage was confirmed by computed tomography (CT) scan, at surgery, or at autopsy. Prior to the acquisition of CT, 23 patients had lumbar puncture which disclosed bloody cerebrospinal fluid. Of the 132 children studied, 128 presented with a specific neurological syndrome. Three lesions were detected incidentally at autopsy, and one pontine AVM was detected in follow-up examination of a patient with a large cranio-orbital vascular malformation. Of eight patients who presented without hemorrhage or seizures, four had delayed development, three had congestive heart failure, and one had chronic headache. Clinical follow-up was evaluable from fifteen months to many years. All patients who received surgical resection are being followed or were followed to the age of 18 years. The locations of AVM in this series are compared to the general adult series of Jomin et al. ${ }^{9}$ (Table 1).

\begin{tabular}{lcc}
\hline Table 1: AVM Location (General Pediatric versus Adult Series) \\
\hline \hline
\end{tabular}

\section{Treatment Methods}

Table 2 details the treatment methods used for 132 patients with brain AVM. Non-operative management was performed in 27 children $(21 \%)$, usually following terminal hemorrhage that produced coma and subsequent death. Surgery was performed within 24 hours of admission in $40 \%$ of patients. Total AVM resection was performed at the first surgical procedure in 60 patients, and partial removal was performed in nine. Six children had placement of a ventriculo-peritoneal shunt. Seven patients had clipping of feeding arteries supplying the AVM (two patients had additional clipping at a second procedure).

In an additional 10 patients, complete AVM resection was achieved at a second operation (usually within two weeks of the first procedure). Further partial resection was performed in one child. Surgery was performed in 82 of 104 children (79\%) that presented with hemorrhage. Surgical resection of the AVM was performed in 15 of 16 patients $(94 \%)$ who presented with seizures.

\section{RESULTS}

\section{Clinical Outcome}

The subarachnoid hemorrhage grade (Botterell) ${ }^{12}$ was correlated with long-term clinical outcome in 102 patients who sustained hemorrhage and in whom follow-up was available (Table 3 ). Two patients in the hemorrhage group of 104 were lost to follow-up. Patients presenting with hemorrhage in good clinical grade (Botterell I and II) had good recovery (79 and $71 \%$ normal respectively). Those who developed a neurological deficit have maintained a good quality of life. A normal outcome occurred in 22 of 28 Grade III patients (79\%) and 9 of 18 Grade

Table 2: Treatment Methods for 132 Children with AVM

\begin{tabular}{lc}
\hline \hline Method & Number of Patients (\%) \\
\hline non-operative & $27(20.5)$ \\
surgery & \\
$\quad$ - total resection first procedure & $60(45.5)$ \\
$\quad$ - partial resection first procedure & $9(6.8)$ \\
- feeding arteries clipped first procedure & $7(5.3)$ \\
- total resection second procedure & $10(7.6)$ \\
- partial resection second procedure & $1(0.8)$ \\
- feeding arteries clipped second procedure & $2(1.5)$ \\
- hematoma evacuation as first procedure & $8(6)$ \\
ventriculo-peritoneal shunt & $6(4.5)$ \\
intravascular embolization attempted & $2(1.5)$ \\
\hline
\end{tabular}

Table 3: Admission Subarachnoid Hemorrhage (SAH) Grade versus Long-Term Clinical Outcome $(n=102)$

\begin{tabular}{cccc}
\hline \hline SAH Grade & Normal & $\begin{array}{c}\text { Number of Patients } \\
\text { Neurological Deficit }\end{array}$ & Dead \\
\hline I & 11 & 3 & 1 \\
II & 15 & 4 & 2 \\
III & 22 & 5 & 1 \\
IV & 9 & 6 & 3 \\
V & 1 & 0 & 19 \\
\hline
\end{tabular}


IV patients $(50 \%)$. Eighteen of 19 patients $(95 \%)$ admitted in Grade V condition died.

In 103 patients (with all presentations) still living for whom follow-up was attainable, $69(67 \%)$ are neurologically normal. Post-operative seizures developed in 12 patients (11.3\%); all were well controlled with anti-convulsant medication. A fixed neurological deficit persisted in 28 patients $(27 \%)$. Progressive mental status deterioration occurred in another five, and one patient has had persistent chronic headache.

Non-operative management was performed in 27 children. In 13 patients, death followed poor-grade hemorrhage, either prior to surgical intervention or in children where surgery offered no chance for clinical recovery; an additional 3 patients had incidental AVMs discovered at autopsy. Three patients were lost to follow-up. Of 8 children still living with their AVMs intact, six are normal, one has a seizure disorder, and one has a persistent neurologic deficit.

\section{Hemorrhage Mortality and AVM Location}

Table 4 details the mortality from hemorrhage versus AVM location in children before and after the introduction of CT at our institution. For all locations, the overall mortality from hemorrhage before CT $(39 \%)$ was reduced significantly in the CT era $(16 \%)$ (chi-square $=5.92 ; p<0.02$ ). When stratified by location (cerebral hemisphere, diencephalon, cerebellum or brainstem) the mortality rate was reduced in each group, but this reduction reached statistical significance only for diencephalic AVMs $(p<0.01)$. The persistently high mortality associated with hemorrhage from a cerebellar AVM was related uniformly to large hematoma formation and rapid brainstem compression.

\section{Surgical Results}

Feeding arteries supplying the AVM were clipped in 7 patients in an attempt to reduce blood flow through the malformation. One patient later had total AVM resection at a second procedure and one had partial resection. In follow-up, 4 of these 7 children remained in normal condition, one had a seizure disorder, one had a fixed deficit and one rebled (four times).

Nine children were left with only partial AVM resection after one or two procedures. Two died later of re-hemorrhage. Four patients remained in normal neurological condition, one had mental status deterioration, one had seizures, and one had a fixed deficit. Six children who had evacuation of hematoma as the first surgical procedure, had subsequent complete AVM

\begin{tabular}{|c|c|}
\hline Location & $\begin{array}{c}\text { Mortality } \\
\text { [number of patients }(\%)]\end{array}$ \\
\hline \multicolumn{2}{|c|}{ Prior to $\mathrm{CT}$} \\
\hline $\begin{array}{l}\text { cerebral hemisphere } \\
\text { diencephalon } \\
\text { cerebellum } \\
\text { brainstem }\end{array}$ & $\begin{aligned} 4 / 25 & (16) \\
4 / 4 & (100) \\
2 / 3 & (67) \\
6 / 9 & (67)\end{aligned}$ \\
\hline \multicolumn{2}{|c|}{ CT Era } \\
\hline $\begin{array}{l}\text { cerebral hemisphere } \\
\text { diencephalon } \\
\text { cerebellum } \\
\text { brainstem }\end{array}$ & $\begin{aligned} 2 / 44 & (4.5) \\
0 / 3 & (0) \\
8 / 14 & (57) \\
0 / 2 & (0)\end{aligned}$ \\
\hline
\end{tabular}

resection; five had a normal outcome and one had a persistent neurological deficit. Complete AVM resection was performed in 70 children. 49 patients (70\%) had a normal neurological outcome, 11 children had persistent deficits, 7 had a seizure disorder and one had deterioration in mental status. One patient died on the day following surgery; one patient died remotely of causes unrelated to the AVM. Surgical resection provided complete relief from seizures (off anticonvulsant medication) in 11 of $15(73 \%)$ children. No patient had evidence of normal perfusion breakthrough syndrome after surgery. ${ }^{13}$

\section{Recurrent Hemorrhage}

In order to confirm completeness of AVM resection, a postoperative angiogram was performed in 87 of 90 children surviving surgery. Recurrent hemorrhage developed in 5 of 23 patients $(22 \%)$ treated either conservatively or with partial AVM resection. In two recent patients with arteriovenous malformations of the temporal lobe, post-operative angiography using standard modern techniques showed no residual malformation; each patient then presented three years later with local re-hemorrhage. Repeat angiography showed a small AVM not seen on the first post-operative study. This indicates that angiography may have limitations in confirming complete resection. One of the postoperative studies was performed three months after surgery, at a time when edema or hematoma would be unlikely to compress the residual lesion.

\section{Discussion}

\section{Natural History of Pediatric AVMs}

Matson declared the AVM as the "most frequent abnormality of the intracranial circulation in childhood". ${ }^{14}$ Despite its prevalence, the natural history of AVMs in the pediatric population is not well understood. In this series, $79 \%$ of AVMs presented with hemorrhage, a rate higher than that reported for adults. ${ }^{6,10} \mathrm{By}$ defining our pediatric population as patients to age 18 years, we do not imply that there are differences between AVMs in patients of 17 versus 20 years of age, but rather between the populations of children and adults. Celli et al. reported a hemorrhage rate over $80 \%$ for children with AVM less than $2 \mathrm{~cm}$ in diameter. ${ }^{15}$ Mori et al. concluded that the prognosis was less favorable in children with AVMs in comparison to adults, and described a higher mortality rate in younger patients due to hemorrhage. ${ }^{1}$ Gerosa et al. reported that the primary hemorrhage was fatal in $5.4 \%$ ( 3 of 56 patients), but that rebleeding occurred in $29 \%$ and carried a grim prognosis. ${ }^{16}$

The higher mortality rate of AVM hemorrhage in children ( $25 \%$ over our entire series) may be due to several factors. First, there may be a higher incidence of AVM location in the posterior fossa (Table 1) where the effects of hemorrhage are more critical. Fults et al. reported mortality in 4 of 6 patients with AVM after posterior fossa hemorrhage. ${ }^{17} \mathrm{~A}$ significant difference was found in comparison between the number of children with posterior fossa AVM in our series (31 of 132) and the general adult series of Jomin et al. $(8$ of 150$)(p<0.0001) .^{9}$ Similarly, infratentorial AVMs were present in only 32 of 453 patients in the Co-operative Study; again this difference was significant ( $\mathrm{p}$ $<0.0001) .{ }^{10}$ We believe that the hemodynamic, compressive or hemorrhagic effects of a critically located infratentorial AVM lead to an earlier symptomatic onset when compared to most 
supratentorial malformations. Second, hemorrhage from a pediatric AVM may be more severe than in adults. Celli et al. stated that cerebral hemorrhages in children show more violent and massive bleeding, demonstrated by a higher frequency of intraparenchymal and intraventricular hemorrhage. ${ }^{15}$ There is no evidence to suggest that the vessels of a younger AVM are more fragile than in the adult. The Co-operative Study reported an adult mortality rate from hemorrhage between 6 and $10 \% .^{10}$

Large series of adult patients with AVM have indicated that the risk for re-hemorrhage is $2-4 \%$ per year, independent of prior hemorrhage.$^{5,7,8,17-20}$ Risk estimates were provided by large series of patients managed conservatively. The lack of prior large pediatric AVM series and the small number of patients without resection in this series, prohibits a reasonable estimate of the re-bleeding risk in children. We speculate that this risk my be slightly higher in adults, due to the overall higher risk of hemorrhage.

\section{Seizures}

Chronic epilepsy, once thought to be the predominant syndrome of the pediatric AVM, is now known to play a much smaller role in comparison to hemorrhage. Gerosa and colleagues reported epilepsy in $18 \%$ of their series, ${ }^{16}$ similar to the incidence of $12 \%$ in this report. LeBlanc et al. and Yeh et al. reported that surgical excision of an AVM and associated epileptogenic tissue (in a patient presenting with related epilepsy) was followed by relief of further seizures in over $70 \%$ of patients. ${ }^{21,22}$ In fifteen of our patients who had surgical resection for seizures, $11(73 \%)$ became seizure-free off anti-convulsant medication. Our resections did not include cortical mapping techniques.

\section{Arteriovenous Malformations of the Brainstem}

Brainstem AVMs present with hemorrhage or a neurological syndrome such as ocular dysfunction or ataxia, and appear to be a mixed group of intraparenchymal and subpial lesions. ${ }^{23}$ They may be intricately woven into the normal blood supply of the brainstem. Logue and Monckton described that "at operation it may be impossible to differentiate angiomatous vessels from the hypertrophied normal arteries which are supplying both brainstem and angioma". ${ }^{24}$ In contrast, several authors reported the complete removal of subpial brainstem AVMs with a good postoperative result. ${ }^{25-27}$ Solomon and Stein reported 12 patients with brainstem AVM; 8 of 9 patients had a complete resection at surgery. ${ }^{28}$ Although five patients had new neurological deficits after surgery, three recovered within one year. There were 11 hemorrhages in our 14 patients with brainstem AVM. Most of these patients presented before CT; six of nine patients who sustained hemorrhage died. There were no hemorrhages in patients that presented with a focal deficit in subsequent follow-up (minimum three years). All patients surviving hemorrhage except one were explored surgically to attempt excision. Although complete microsurgical resection of a brainstem AVM can be performed, stereotactic radiosurgery may prove to be a valuable treatment alternative to achieve complete obliteration with less morbidity. ${ }^{29,30}$

\section{Angiographically Occult Arteriovenous Malformations}

Five patients with angiographically occult, histologically verified AVM were reported previously, of which three were in children. ${ }^{31}$ These small malformations may be responsible for a major proportion of children who suffer intracerebral hemorrhage of unknown etiology. Magnetic resonance imaging (MRI) has provided an increase in the diagnosis of this lesion, and should follow negative angiography during investigation of intracerebral hemorrhage. A close examination of the hematoma cavity is also warranted to check for this lesion at the time of surgery if not demonstrated by pre-operative imaging studies. In this series, 10 patients $(7.6 \%)$ had angiographically occult arteriovenous malformations; five had presented with hemorrhage. The actual incidence of AOVM was likely higher as many poor grade patients did not undergo angiography, either prior to surgery or to post-mortem. Close follow-up must be maintained in all children with an intracerebral hemorrhage small enough to be treated conservatively; these patients may harbor an occult malformation.

\section{AVM Management Strategies}

Because this series was collected from a 40-year experience with heterogeneous treatment methods, definitive conclusions regarding individual management techniques are difficult to formulate. However, several comments based on this experience can be made. Successful AVM management is dependent upon AVM location, size, hemodynamics, patient clinical condition and treatment method selected. ${ }^{5-7,9,18,29.32 .33}$ Treatment should preserve life and neurological function, while achieving complete removal of the AVM and preservation of the normal cerebral circulation. Long-term conservative management of AVMs in the adult population has been reported, with resultant longterm risk of death and disability. $5,8,19,20,34$

In contrast to adult series, many pediatric studies have emphasized the role of conservative management for selected AVMs. So reserved surgery for patients presenting with hemorrhage. ${ }^{35}$ Complete resection was achieved in 9 of 23 children who had surgery. In his follow-up interval, ten children died; eight had been treated conservatively. For patients presenting with seizures, five were treated with anti-convulsant medication alone, and an additional six received conventional radiotherapy. In follow-up to 7 years, 10 of 14 patients with seizures suffered an intracerebral hemorrhage. Kelly and co-workers reserved surgery for: (a) massive lesions in infants; (b) children with large hematoma associated with the AVM; and (c) patients with a refractory seizure disorder. ${ }^{36}$ They believed that many patients with seizures amenable to medical therapy could be managed effectively without surgery. These patients with seizures (without hemorrhage) did well in 3-year follow-up; and extended evaluation is necessary. Gerosa et al. commented that the poor results seen with conservative treatment in their series (18 of 56 patients) indicated that AVMs were primarily a surgical condition, both for lesions which have or have not bled. ${ }^{16}$ If we accept a hemorrhage rate of $2-4 \%$ per year (and possibly higher), we must also accept the greater devastation of the hemorrhage in children. The significant benefit of CT scanning in helping to make an early diagnosis and facilitate treatment (in most cases evacuation of an intraparenchymal hemorrhage), has greatly reduced mortality. Improved results are also related to the development of microsurgical technique, better neuroanesthesia, and higher quality angiography.

We believe that immediate surgical management is indicated for patients presenting with intracerebral hemorrhage with asso- 
ciated progressive neurological deficit or signs of brainstem compression; surgery can be delayed in clinically stable patients until a proper neuroradiological assessment has been performed and conditions for surgery are optimal. In most of our patients treated surgically within 24 hours for removal of hematoma, we were able to completely resect the AVM. Martin and Edwards tried to delay surgery from two to four weeks after hemorrhage, if the patient remained neurologically stable for delayed surgery. This provided time for further investigation and stabilization of the patient. ${ }^{37}$ Although clipping of feeding arteries was performed as the sole therapeutic procedure in seven patients, we consider this to be an ineffectual treatment method. Microsurgical techniques have improved the safety and feasibility of complete resection, and have eliminated the indications for feeder therapy alone. Amacher et al, reported that simple clipping of feeders was ineffective, as other vessels open up to feed the malformation. ${ }^{38}$

\section{Alternative Treatment Methods}

Intravascular embolization was used in only two patients. Although staged embolization and resection was reported to be of benefit for large AVMs (> $6 \mathrm{~cm}$ diameter), ${ }^{39}$ no children in this series had such large malformations. In one neonate who presented at day two of age with severe congestive heart failure and hemorrhage associated with a large middle cerebral territory AVM, attempted embolization was unsuccessful. The tortuous middle cerebral artery could not be entered. Godersky et al. reported successful embolization of a posterior fossa AVM in a six-month-old child suffering from congestive heart failure. ${ }^{40}$ The patient had cardiac improvement without a surgical procedure. One patient in our series with an AVM of the pons (presenting with a cranial nerve palsy) was referred for stereotactic radiosurgery. Treatment was refused by the parents. The role of radiosurgery for treating $\mathrm{AVMs}$ in children remains to be defined, although encouraging results in carefully selected patients are reported. 29,30

\section{Conclusion}

Treatment of a child with an AVM using one or more techniques is indicated in order to eliminate the risk of intracranial hemorrhage over the remaining decades of life. For patients who have sustained prior hemorrhage (and they represent the majority), the goal should be rapid extirpation of the malformation. In most patients, this can be achieved safely with open microsurgical excision. Although excellent results exist for children surviving hemorrhage who undergo surgery, the mortality of hemorrhage remains high.

\section{ACKNOWLEDGEMENTS}

This paper was presented at the 58th meeting of the American Association of Neurological Surgeons, Nashville, Tennessee, April 1990.

\section{REFERENCES}

1. Mori K, Murata T, Hashimoto N, et al. Clinical analysis of arteriovenous malformations in children. Childs Brain 1980; 6: 13-25.

2. McCormick WE. Pathology of vascular malformations of the brain. In: Wilson C, Stein B, eds. Intracranial Arteriovenous Malformations. Baltimore: Williams and Wilkins, 1984: 44-63.
3. Padget DH. The cranial venous system in man in reference to development, adult configuration and relation to the arteries. Am J Anat 1956; 98: 307-355.

4. Takashima S, Becker LE. Neuropathology of cerebral arteriovenous malformations in children. J Neurol Neurosurg Psychiatry 1980; 43: 380-385.

5. Graf CJ, Perret GE, Torner JC. Bleeding from cerebral arteriovenous malformations as part of their natural history. $J$ Neurosurg 1983; 58: 331-337.

6. Guidetti B, Delitala A. Intracranial arteriovenous malformations. Conservative and surgical treatment. J Neurosurg 1980; 53: 149152.

7. Heros RC, Korosue K, Diebold PM. Surgical excision of cerebral arteriovenous malformation: late results. Neurosurgery 1990; 26: $578-579$

8. Itoyama Y, Uemura S, Ushio Y, et al. Natural course of unoperated intracranial arteriovenous malformations: study of 50 cases. J Neurosurg 1989; 71: 805-809.

9. Jomin M, Lesoin F, Lozes G. Prognosis for arteriovenous malformations of the brain in adults based on 150 cases. Surg Neurol 1985; 23: 362-366.

10. Perret G, Nishioka $H$. Arteriovenous malformations: An analysis of 545 cases of cranio-cerebral arteriovenous malformations and fistulae reported to the Co-operative Study. J Neurosurg 1966; 25: $467-490$

11. Humphreys RP. Hemorrhagic stroke in childhood. J Pediatr Neurosci 1986; 2: 1-10.

12. Botterell EH, Lougheed WM, Scott JW, et al. Hypothermia, and interruption of carotid, or carotid and vertebral circulation, in the surgical management of intracranial aneurysms. J Neurosurg 1956; 13: 1-42.

13. Spetzler RF, Wilson CB, Weinstein $P$, et al. Normal perfusion pressure breakthrough theory. Clin Neurosurg 1977; 25: 651-672.

14. Matson DD. Neurosurgery of Infancy and Childhood. Springfield: Thomas, 1969: 749-766.

15. Celli P, Ferrante L, Palma L, et al. Cerebral arteriovenous malformations in children. Clinical features and outcome of treatment in children and in adults. Surg Neurol 1984; 22: 43-49.

16. Gerosa MA, Cappellotto P, Licata C, et al. Cerebral arteriovenous malformations in children ( 56 cases). Childs Brain 1981; 8: 356371 .

17. Fults D, Kelly DL. Natural history of arteriovenous malformations of the brain: A clinical study. Neurosurgery $1984 ; 15: 658-662$.

18. Crawford PM, West CR, Chadwick DW, et al. Arteriovenous malformations of the brain: natural history in unoperated patients. J Neurol Neurosurg Psychiatry 1986; 49: 1-10.

19. Ondra SL, Troupp H, George ED, et al. The natural history of symptomatic arteriovenous malformations of the brain: a 24-year follow-up assessment. J Neurosurg 1990; 73: 387-391.

20. Wilkins RH. Natural history of intracranial vascular malformations: A review. Neurosurgery 1985; 16: 421-430.

21. Leblanc R, Feindel W, Ethier R. Epilepsy form cerebral arteriovenous malformations. Can J Neurol Sci 1983; 10: 91-95.

22. Yeh HS, Kashiwagi S, Tew JM, et al. Surgical management of epilepsy associated with cerebral arteriovenous malformations. J Neurosurg 1990; 72: 216-223.

23. Humphreys RP, Hendrick EB, Hoffman HJ. Arteriovenous malformations of the brainstem in childhood. Childs Brain 1984; 11: 1-11.

24. Logue V, Monckton G. Posterior fossa angiomas. A clinical presentation of nine cases. Brain 1954; 77: 252-273.

25. Drake CG. Cerebral arteriovenous malformations: considerations for and experience with surgical treatment in 166 cases. Clin Neurosurg 1979; 26: 145-208.

26. Russo RH, Dicks RE. Arteriovenous malformations of the brain stem in childhood. Surg Neurol 1977; 8: 167-170.

27. Sundaresan N, Galicich J, Krol G, et al. Successful surgical treatment of pontine vascular malformation in a 3-year old. Childs Brain 1979; 5: 131-136.

28. Solomon RA, Stein BM. Management of arteriovenous malformations of the brain stem. J Neurosurg 1986; 64: 857-864.

29. Altschuler EM, Lunsford LD, Coffey RJ, et al. Gamma Knife radiosurgery for intracranial arteriovenous malformations in childhood and adolescence. Pediatr Neurosci 1989; 15: 53-61. 
30. Lunsford LD, Kondziolka D, Flickinger JC, et al. Stereotactic radiosurgery for arteriovenous malformations of the brain. $J$ Neurosurg (in press).

31. Cohen HCM, Tucker WS, Humphreys RP, et al. Angiographically occult histologically verified cerebrovascular malformations. Neurosurgery 1982; 10: 704-714.

32. Garza-Mercado R, Caravos E, Tamez-Montes D. Cerebral arteriovenous malformations in children and adolescents. Surg Neurol 1987; 27: 131-140.

33. Humphreys RP, Hendrick EB, Hoffman HJ. Arteriovenous malformations of the brain. Concepts Pediatr Neurosurg 1988; 8: 146164.

34. Forster DMC, Steiner L, Hakanson S. Arteriovenous malformations of the brain. A long-term clinical study. J Neurosurg 1972; 37: $562-570$.

35. So SC. Cerebral arteriovenous malformations in children. Childs Brain 1977; 4: 242-250.
36. Kelly JJ, Mellinger JF, Sundt TM. Intracranial arteriovenous malformations in childhood. Ann Neurol 1978; 3: 338-343.

37. Martin NA, Edwards MSB. Supratentorial arteriovenous malformations. In: Edwards M, Hoffman H, eds. Cerebral Vascular Disease in Children and Adolescents. Baltimore: Williams and Wilkins, 1989: 283-308.

38. Amacher AL, Drake CG, Hovind L. The results of operating upon aneurysms and angiomas in children and adolescents. Part II: cerebral angiomas. Childs Brain 1979; 5: 166-173.

39. Spetzler RF, Martin NA, Carter LP, et al. Surgical management of large AVMs by staged embolization and operative excision. J Neurosurg 1987; 67: 17-28.

40. Godersky JC, Menezes AH. Intracranial arteriovenous anomalies in infancy: modern concepts. Pediatr Neurosci 1987; 13: 242-250. 